\section{Linear Electro-optic Effects in Tetragonal Arsenates}

THE crystals of potassium dihydrogen arsenate (KDA, $\mathrm{KH}_{2} \mathrm{AsO}_{4}$ ) and its isomorphs, belonging to the point group symmetry $\overline{42} \mathrm{~m}$, crystallize in the tetragonal system in the paraelectric phase at room temperature. This group, together with the $\overline{43} \mathrm{~m}$ symmetry group of the eubic system, are the only crystals which possess linear electro-optic effect free of background birefringence. 'The crystals of the first group, however, possess relatively largo electro-optic constants. These crystals have been grown in an effort to find better electro-optic modulators. Measurements of the half-wave retardation voltage $V \lambda / 2$ performed on these single crystals aro presented here.

Electro-optic modulator applications of ADP type erystals were pioneered by Gotschall ${ }^{1}$ and by Billings ${ }^{2}$. Because the principal uses of these crystals are in laser technology, these materials have been investigated recently $y^{3,4}$. Single crystals of these tetragonal arsenates were grown in conventional Holden erystallizers with suitable modification. Good quality crystals, free of strains and veils, were obtained by growing them in several successive growth cycles. The proportion of deuterium in deuterated crystals was more than 90 per cent.

Direct measurements of the half-wave voltage $V \lambda / 2$ were made on carefully oriented samples $\left( \pm \frac{1}{2}\right)$ of $0^{\circ} \mathrm{Z}$ cut bars $(L=1 \mathrm{~cm}, W=0.5 \mathrm{~cm}, T=0.5 \mathrm{~cm})$. The end faces were polished to optical finish and a thin layer of gold film (100 $\AA$ or so) was deposited on these faces, to which leads were attached by conductive epoxy, for applying a de voltage. 'The bars were then placed in the measuring system of a precision spectro-polarimeter, formed by a mercury xenon are lamp, quartz prism monochromator, Glan-Thomson polarizing prisms and a multirange photomoter with sensitivity range up to 0.1 nA, using a 931 A photomultiplier tubo. High vol. tages were measured to an accuracy of \pm 1 per cent with a Keithley clectrometer, fitted with a high voltage probe. Both the polarizer and analyser were set to $0^{\circ}$ with respect to the $X$ and $Y$ axis of these $0^{\circ} \mathrm{Z}$ samples. The half-wave retardation voltage $V \lambda / 2$ is the voltage at which minimum intensity is obtained at a given wavelength. During these measurements a monochromatic light of half intensity bandwidth varying from $30 \AA$

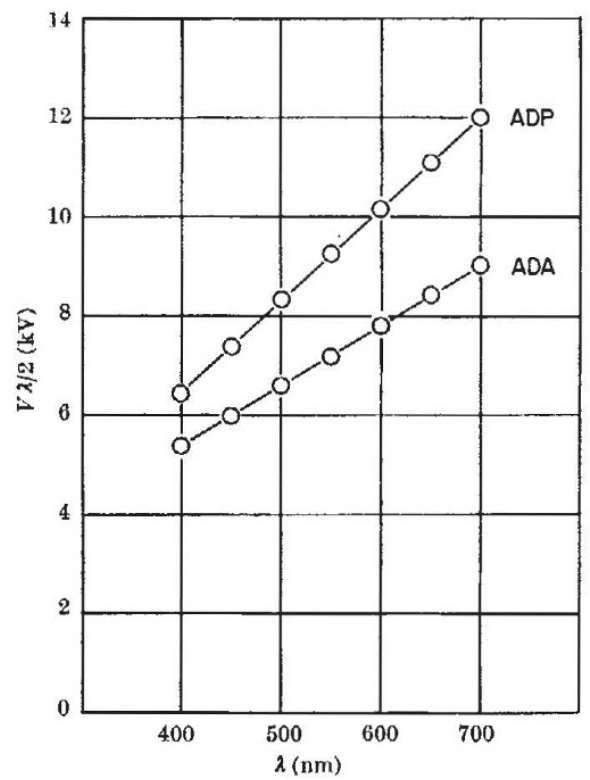

Fig. 1. $V \lambda / 2$ against $\lambda$ for ADP and ADA single crystals.

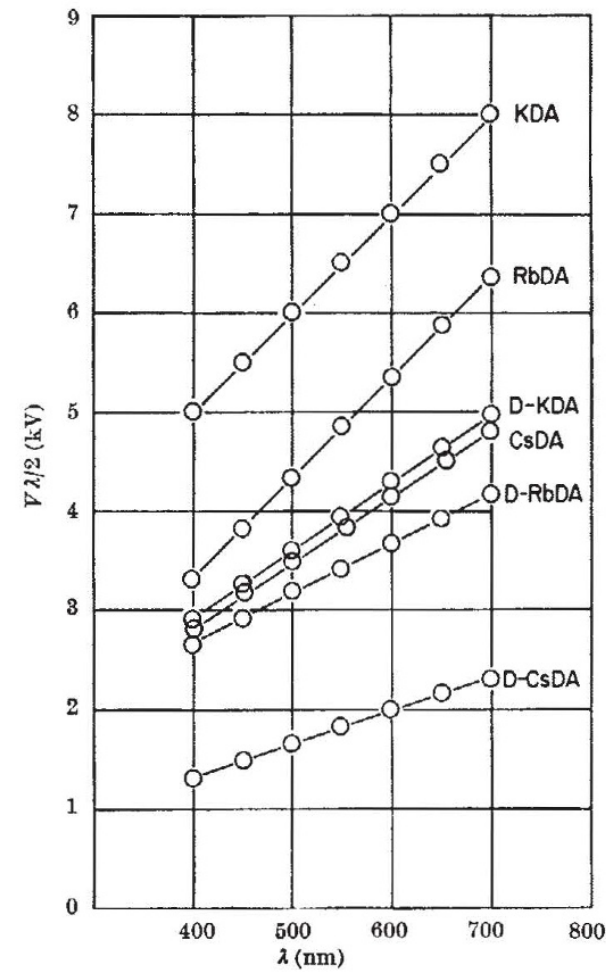

Fig. 2, $\nabla \lambda / 2$ against $\lambda$ for KDA, D-KDA, RbDA, D-RbDA, CsDA and D-CBDA single crystals.

(at $400 \mathrm{~nm}$ ) to $100 \AA$ (at $700 \mathrm{~nm}$ ) was allowed to enter the slit. It is estimated that the overall measurement accuracy is about 3 per cent

These measurements of $V \lambda / 2$ on ADP and ADA crystals are shown in Fig. 1 and those on KDA, D-KDA, RhDA, D-RbDA, CsDA and D-CsDA are shown in Fig. 2. This value at $550 \mathrm{~nm}$ of $7.20 \mathrm{kV}$ for ADA single crystal differs considerably from that of $13 \mathrm{kV}$, published in the AIP handbook ${ }^{5}$. The simple crystals of D-CsDA require the lowest half-wave retardation voltage $(1.95 \mathrm{kV}$ at $550 \mathrm{~nm})$ among these isomorphs, and these should find an important place in modulator applications where lower $V \lambda / 2$ is a major criterion. Detailed investigations on these single crystals will be published later.

This research was supported in part by a grant from the Department of Industrial Research of the Defence Research Board, Ottawa, and by a contract from the Rome Air Development Centre, Griffiss Air Force Base, New York.

Edo (Canada) Ltd,

R. S. Adhav

Cornwall, Ontario, Canada.

Received October 21, 1968.

${ }^{1}$ Gotschall, G. D., J. Soc. Motion Picture Eng., 51, 13 (1948).

${ }^{2}$ Billings, B. H., J. Opt. Soc. Amer., 38, 797 (1949).

${ }^{3}$ Ott, J. H., and Sliker, T. R., J. Opt. Soc. Amer., 54, 1442 (1964).

4 Adhav, R. S., J. Appl. Phys. (1968).

${ }^{5}$ ATP Handbook (edit, by Gray, D. F.), 6 (McGraw-Hill, New York, 1957).

\section{Nuclear Magnetic Resonance in Phase Study: $\mathrm{LiCl}-\mathrm{CrCl}_{3}$}

THERE is evidence for reaction between mixtures of pure anhydrous $\mathrm{LiCl}$ and $\mathrm{CrCl}_{3}$ when they are fused at between $500^{\circ}$ and $700^{\circ} \mathrm{C}$, and the resultant melts are cooled. An equation can be written

$$
\left(\mathrm{CrCl}_{3}\right)_{\mathrm{x}}+3 \mathrm{x} \mathrm{LiCl} \rightarrow \mathrm{x} \mathrm{CrCl}_{6}{ }^{3-}+3 \mathrm{x} \mathrm{Li}^{+}
$$

